\title{
FIRST DATE WITH THE HIVE
}

\section{Mind how you go.}

\section{BY GRETCHEN TESSMER}

$\mathrm{H}$ onestly, I was disappointed. All those science-fiction movies I grew up on promised me lizardlike aliens, bug-eyed aliens and, at the very least, some aliens with green skin. But when Graz/dash Elias VIII and his small team of first contactors made their descent in the North Atlantic, deciding to dock at the first available speck of rock in Lobster Land, state of Maine, there was no awe-struck reception. In fact, they crashed a wedding and the over-worked and underpaid wedding photographer, who had just positioned the bridal party within view of both the perfect ocean spray and the Nubble Lighthouse, swore at them to get out of the goddamn shot.

Because, spoiler alert, they looked exactly like us. They dressed like us, ate and drank like us, and spoke like us. They knew all our languages and seemed shocked that we would be impressed by their rudimentary linguistic abilities. After all, explained Mersa Seryann-Shale, Graz/dash Elias VIII's more business-like second-in-command, there's a finite number of sounds in the Universe. Good to know there's only so many ways to say, "Would you like fries with that?"

"It isn't rocket science," Graz/dash Elias VIII added, cleverly, grinning at the old joke like he'd grown up in the same schoolyards as us.

He endeared himself to the first interviewers, told us all to call him Dash and welcomed questions from political dignitaries and common people alike. Where are you from? The Andromeda Galaxy, obviously. It's the best one. Are you like us? Sure. Bipeds, with an unhealthy affinity for sugar. Why have you come? To say hello and invite you to join the Hive. What's the Hive? It's a collection of various races, creeds and nationalities from our two galaxies that have agreed to live in peace and prosperity forever and ever, amen.

Yeah, I thought it sounded a little too good to be true myself. But I work in food service, 3-11 shift at Wendy's, so what do I know? President What's-His-Name seemed convinced and invited Dash and his team to the White House.

Dash said they'd be delighted and, with

$\rightarrow$ NATURE.COM Follow Futures: @ @NatureFutures f go.nature.com $/ \mathrm{mtoodm}$ a TV-ready grin, complimented our "quaint, old-fashioned" ways. The photo ops were great.

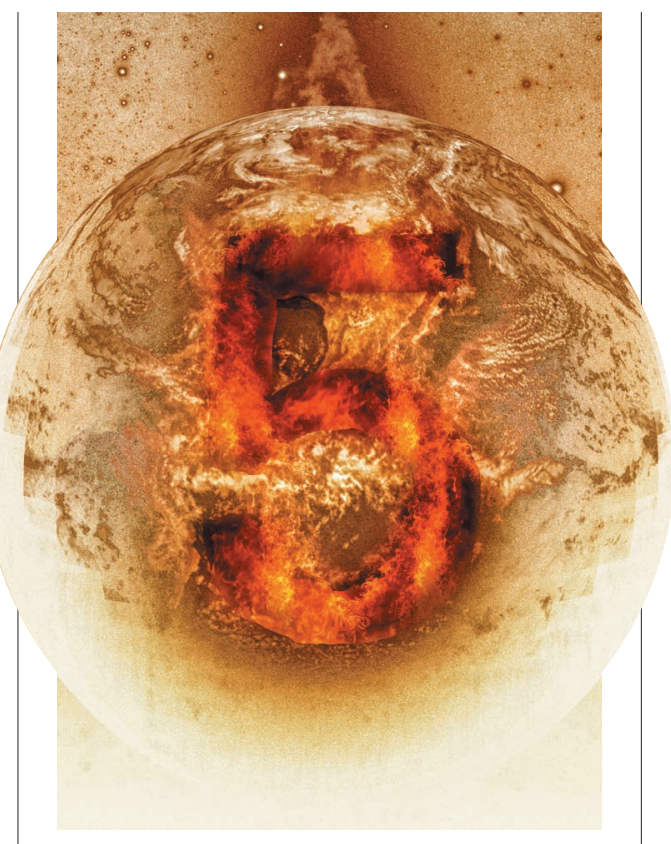

No one talked about anything else for weeks.

But then Dash got down to business. He, Mersa and the rest were actually on a deadline so they needed an answer to the "joining the Hive" thing pretty much immediately.

A fleet of aggressively armed ships above our planet suddenly materialized out of whatever cloaking devices had been hiding them in the higher reaches of our atmosphere. From where I was standing in the Wendy's parking lot, it looked very much like a Spanish-Armada-with-intent-tooverthrow-Elizabeth-style fleet.

So, President What's-His-Name said yes in a hurry. But it turns out there's a little more to it than that. Dash's team rounded up a random bunch of us from the DC area and held a presentation on the steps of the Lincoln Memorial.

"Okay, so here's how it works," he began bluntly. "And we're all adults so I'll just split the star for you."

"I don't think that's a saying they would understand," Mersa mentioned from where she sat, lounging on Lincoln's shoulder, some sort of high-tech, pistol-shaped weapon in her right hand that we hadn't yet decided to test out. The shadows of the ships above us were blocking out all rays of sunshine.

"It's a common saying, Mersa," Dash countered.

"He means 'lay it on you," she addressed the crowd, while giving Dash a heavy side eye.
"Anyway," Dash continued. "The Hive has been good for us. We understand each other. We all speak the same language. As in, we know what each other is thinking. Literally. That's right, ladies and gentlemen, our brains are connected. Yours too. Hopefully, you've figured out how to use the relevant portions of your marvellous brains ... though from the confused thoughts coming at me from the front row, I'm getting a serious 'no' vibe."

"You're mind-readers?" President What's-His-Name rolled his eyes and looked generally sceptical.

But the benevolent alien thing he believes? I thought to myself.

"My thoughts exactly," Dash looked at me and I swallowed hard. "So, yeah, psychics, mind-readers, telepaths, whatever you want to call us. It's a very important part of our combined culture. Streamlined communication is a necessity in this day and age.

"However, as you may or may not be comprehending... we don't really have time to teach you the ropes. We're progressives. Manifest destiny, am I right? And if your 'mind-reading' abilities are still dormant at this stage in your evolution, I'm calling a lost cause. How about you, Mersa?"

"Shut up, Dash," she said, growing tired of the subterfuge. "Just do it already."

"Okay." Dash rubbed his hands together in anticipation. "I need five volunteers. Random sample. You, you, yes, you in the backwards baseball cap, no, not you $\mathrm{Mr}$ President, you with the hot red lipstick, very nice, annnnnd ..." he looked at me and smiled, "oh yeah, you, Wendy-girl."

We were told to line up in front of him. Mersa jumped down from her perch and had her weapon drawn on the crowd.

"It's a simple thing," Dash smiled kindly. "And I'll give you five chances."

Five chances for what?

"Don't interrupt," Mersa answered my unasked question.

"Sorry," I mumbled.

"I'm thinking of a number between 1 and oh, how about 2 trillion? You have five chances to read my mind. If you get it right, welcome to the Hive. If not..." Dash looked at each of us in turn, ending on me. "Well, you have one hour. Go." -

Gretchen Tessmer is an attorney/writer based in the US/Canadian borderlands of northern New York. Follow her on Twitter: @missginandtonic 